\title{
ULTRA-TRACE MONITORING OF COPPER IN ENVIRONMENTAL AND BIOLOGICAL SAMPLES BY INDUCTIVELY COUPLED PLASMA ATOMIC EMISSION SPECTROMETRY AFTER SEPARATION AND PRECONCENTRATION BY USING OCTADECYL SILICA MEMBRANE DISKS MODIFIED BY A NEW SCHIFF'S BASE
}

\author{
Mohammad Reza Ganjali*, Mohammad Reza Pourjavid and Leila Haji-agha Babaei \\ Department of Chemistry, Tehran University, P.O. Box 14155-6455, Tehran - Iran \\ Masoud Salavati-Niasari \\ Department of Chemistry, Kashan University, Kashan - Iran
}

Recebido em 26/2/03; aceito em 24/10/03

\begin{abstract}
Ultra-trace amounts of $\mathrm{Cu}(\mathrm{II})$ were separated and preconcentrated by solid phase extraction on octadecyl-bonded silica membrane disks modified with a new Schiffs base ( Bis- (2-Hydroxyacetophenone) -2,2-dimethyl-1,3-propanediimine) (SBTD) followed by elution and inductively coupled plasma atomic emission spectrometric detection. The method was applied as a separation and detection method for copper(II) in environmental and biological samples. Extraction efficiency and the influence of sample matrix, flow rate, $\mathrm{pH}$, and type and minimum amount of stripping acid were investigated. The concentration factor and detection limit of the proposed method are 500 and $12.5 \mathrm{pg} \mathrm{mL}^{-1}$, respectively.
\end{abstract}

Keywords: copper; solid phase extraction; Shiff's base.

\section{INTRODUCTION}

The role of trace transition and heavy metal ions in animal and plant biological systems is very important, but very complex. A lake of some of these microelements in an organism can cause many diseases and illnesses, however, their sufficient quantities can also induce many harmful consequences. The most frequently present copper ion is introduced into human and animal bodies by food, water, air, etc. On the other hand, rain, snow, fertilizer and water of irrigation are the most common routes for copper introduced into plants ${ }^{1}$.

Human can not exist without food and drinking water. Therfore, the development of accurate and rapid determination method for monitoring the level of copper in water and food is necessary and indispensable.

The most common methods for determination of copper ion are flame and graphite furnace atomic absorption spectrometry ${ }^{2}$, spectrophotometry ${ }^{3}$, constant current stripping analysis ${ }^{4}$, differential pulse anoding stripping voltametry ${ }^{5}$, potentiometry ${ }^{6}$ and inductively coupled plasma atomic emission spectrometry ${ }^{7}$. But, their sensitivity is usually insufficient for very low concentrations in environmental and biological samples. Thus, a preconcentration and matrix elemination step is usually required. The most widely used techniques for the separation and preconcentration of trace amounts of copper ions are liquid-liquid extraction (LLE) $)^{8,9}$, precipitation and cation exchange resins ${ }^{10}$, absorption of their complexes on the microcrystalline benzophenone ${ }^{11}$ and solid phase extraction (SPE) ${ }^{12}$.

Solid phase extraction (SPE) is an alternative technique that reduces solvent usage and exposure, disposal cost, and extraction time for sample preparation ${ }^{13}$. Recently, hydrophobic SPE disks have been used extensively for the determination of organic environmental polluents ${ }^{14,15}$. These disks, made of $90 \%(w / w)$ octadecyl silane in an inert polytetrafluoroethylene matrix, have atypical diameter of $47 \mathrm{~mm}$ and a thickness of $0.5 \mathrm{~mm}$. Typical capacity of a disk for well-retained compounds ranges from 10 to $20 \mathrm{mg}$. The proclaimed major

*e-mail: Ganjali@khayam.ut.ac.ir advantages of the SPE disks include (1) shorter sample processing time due to the large cross-sectional area of the disk and decreased pressure drop, which allows the sample processing at higher flow rates, (2) decreased plugging by particles due to large cross-sectional area of the disk and (3) reduced channeling resulting from the use of smaller diameter sorbent and a greater mechanical stability of the sorbent bed ${ }^{16}$.

We have recently reported solid phase extraction and atomic absorption determination of some cations including $\mathrm{Cu}^{2+}, \mathrm{Pb}^{2+}, \mathrm{Ag}^{+}$ and $\mathrm{Ce}^{3+17-22}$. In this paper we reported the solid phase extraction and determination of ppt amounts of copper in environmental and biological samples using octadecyl silica membrane disks modified with a new Schiff base (SBTD, Figure 1) and inductively coupld plasma atomic emission spectrometry.

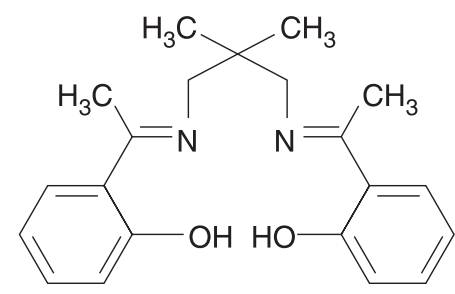

Figure 1. Structure of SBTD

\section{EXPERIMENTAL PART}

\section{Reagents and apparatus}

Hydrochloric acid, hydrobromic acid, acetic acid and nitric acid, high purity methanol, 2-hydroxyacetophenone and 2,2-dimethyl-1,3propanediamine and ethanol (all from Merck) were used as received. Analytical grade nitrate salts of copper, sodium, potasium, magnesium, calcium, strontium, cobalt, nickel, zinc, chromium, silver, barium, lead and cadmium (all from Merck) were of the highest purity available and were dried in a vacuum over $\mathrm{P}_{2} \mathrm{O}_{5}$. 


\section{Digestion of tea and pepper samples}

The procedure used for the extraction of these ions from tea sample was similar to that reported in the literature ${ }^{28} .10 \mathrm{mg}$ of the dry tea sample (dried at $110^{\circ} \mathrm{C}$ ) was placed in a 50 -mL beaker, followed by the addition of $7 \mathrm{~mL}$ of concentrated nitric acid, and the beaker was covered with a glass watch. The beaker was allowed to stand over night, and the contents were heated on a hot plate $\left(150{ }^{\circ} \mathrm{C}\right.$ for $15 \mathrm{~min}$ ). Then the sample was cooled, $8 \mathrm{~mL}$ of perchloric acid was added, and the mixture was heated again at $200{ }^{\circ} \mathrm{C}$ until the solution became clear (about $1 \mathrm{~h}$ ). The glass watch was removed and the acid evaporated to dryness at $150^{\circ} \mathrm{C}$. The residue was completely dissolved in $5 \mathrm{~mL}$ of $1 \mathrm{~mol} \mathrm{~L}^{-1}$ nitric acid and the solution was transferred to a $100 \mathrm{~mL}$ calibrated flask. Then, the solution was neutralized with a proper $\mathrm{NaOH}$ solution and diluted to the mark, and the recommended procedure was followed.

\section{Digestion of standard biological samples}

$10 \mathrm{mg}$ sample was taken in a beaker and dissolved in $5 \mathrm{~mL}$ of concentrated nitric acid with heating. The solution was cooled, diluted and filtered. The filtrate was neutralized with $\mathrm{NaOH}$ diluted to $100 \mathrm{~mL}$ with water in a calibrated flask. An aliquot of the sample solution was taken individually and $\mathrm{Cu}^{2+}$ ions were determined by the general procedure.

\section{Synthesis of SBTD}

2-hydroxyacetophenone ( $0.02 \mathrm{~mL}, 2.72 \mathrm{~g})$ was mixed with 150 $\mathrm{mL}$ of distilled ethanol in a $500 \mathrm{~mL}$ round bottom flask, which was stirred using a magnetic stirrer. 2,2-dimethyl-1,3-propanediamine ( $0.015 \mathrm{~mol}$, or $1.02 \mathrm{~g}$ ) dissolved in $25 \mathrm{~mL}$ of distilled ethanol was added drop by drop, using a dropping funnel to the above solution. The contents were refluxed for $2 \mathrm{~h}$ to get a yellow solid precipitate of Schiff's base ligand, which was cooled, filtered, washed with Petroleum ether and dried. The ligand was then re-crystallized from ethanol.

Analytical calculation of SBTD with formula $\mathrm{C}_{12} \mathrm{H}_{26} \mathrm{~N}_{2} \mathrm{O}_{2}$ is shown $\mathrm{C}, 74.52 ; \mathrm{H}, 7.74 ; \mathrm{N}, 8.28 \%$. Exprimental analysis of SBTD was shown C, 73.94; H, 7.68; N, 8.41\%.

The copper, sodium, potasium, magnesium, calcium, strontium, cobalt, nickel, zinc, chromium and silver determination were carried out on a Varian Liberty 150 AX Turbo.

Extraction were performed with $47 \times 0.5 \mathrm{~mm}$ (diameter $\times$ thickness) Empore membrane disks containing octadecyl-bonded silica (8- $\mu \mathrm{m}$ particles 60 - $\AA$ pore size, $3 \mathrm{M}$ Co.,Paul, MN). The disk was used in conjunction with standard Millipore 47-mm filtration apparatus.

\section{Preparation of the SPE membrane disks}

To remove potential interferences and to ensure optimal extraction of the analyte of interest, the disk cleaning and conditioning should be done before its use. Thus, after placing the membrane disk in the filtration apparatus, $10 \mathrm{~mL}$ of methanol was poured onto the disk immediately drawn through the disk by applying a slight vacuum. Afterall of the solvent has passed through the disk, it was dried by passing air through it for few minutes. The disk conditioning was then begun by pouring $10 \mathrm{~mL}$ of methanol onto the disk and a low vacuum was applied and the solvent was drawn through the disk until the solvent surface almost reached the surface of the disk. The disk should not be allowed to soak without vacuum, and air should not be allowed to wake contact with surface of the disk. It is preferably extra methanol above the disk rather than to allow any air to make contact with the surface of the disk. Immediately, $10 \mathrm{~mL}$ of water was introduced onto the disk and was drawn through the disk. The disk was then dried under vacuum for $5 \mathrm{~min}$, this is especially important for the disks that are used for the first time. Finally, a solution of $5 \mathrm{mg}$ of SBTD dissolved in $4 \mathrm{~mL}$ of methanol was introduced onto the disk so that the solution was spread on the whole disk surface. The solution was allowed to penetrate inside the membrane completely without applying any vacuum. After about $1 \mathrm{~min}$, the filtration funnel containing the modified disk was transferred into an oven and the solvent was completely evaporated at $60{ }^{\circ} \mathrm{C}$. Then the sample solution containing $\mathrm{Cu}^{2+}$ (with $\mathrm{pH}$ about 5) was passed through the membrane. After the extraction, the disk was stripped from the membrane disk using minimum $5 \mathrm{~mL}$ of a 3 mol L-1 nitric acid solution. Then the copper concentration was determined by inductively coupld plasma atomic emission spectrometry (off-line analysis).

\section{RESULTS AND DISCUSSION}

Our recently reserches showed that, the Schiff's base compounds can form a fairly stable and selective complex with transition and heavy metal ions, specially copper ${ }^{23}$. To the best of our knowledge, there is no report on the stability of SBTD complexes with metal ions. Thus, in preliminary experiments, the complexation of SBTD with a number of alkali, alkaline earth, transition and heavy metal ions was studied conductometrically in acetonitrile solution at $25 \pm 0.05{ }^{\circ} \mathrm{C}^{24,25}$, in order to obtain information about the stability and selectivity of the resulting complexes. The complex formation constant, $\mathrm{K}_{\mathrm{f}}$, of the resulting 1:1 complexes were evaluated by computer fitting of the molar conductance-mole ratio data to appropriate equations $\mathrm{s}^{24,25}$, and the results are summarized in Table 1. As can be seen, the SBTD could act as a suitable complexing agent for pre-concentration and separation of copper ions via solid extraction, by using octadecyl bonded silica membrane disks.

Table 1. Stability constants $\left(\mathrm{K}_{\mathrm{f}}\right)$ of SBTD-cation complexes in acetonitrile solution

\begin{tabular}{cc}
\hline Cations & $\log \mathrm{K}_{\mathrm{f}}$ \\
\hline $\mathrm{Na}^{+}$ & $2.72 \pm 0.03$ \\
$\mathrm{~K}^{+}$ & $2.20 \pm 0.04$ \\
$\mathrm{Ca}^{2+}$ & $2.95 \pm 0.05$ \\
$\mathrm{Ba}^{2+}$ & $2.79 \pm 0.06$ \\
$\mathrm{Cu}^{2+}$ & $5.86 \pm 0.07$ \\
$\mathrm{Co}^{2+}$ & $3.95 \pm 0.03$ \\
$\mathrm{Zn}^{2+}$ & $2.98 \pm 0.05$ \\
$\mathrm{Ni}^{2+}$ & $4.01 \pm 0.02$ \\
$\mathrm{~Pb}^{2+}$ & $3.75 \pm 0.04$ \\
$\mathrm{Cd}^{2+}$ & $3.72 \pm 0.02$ \\
\hline
\end{tabular}

\section{Effect of eluent on the stripping of copper}

Some preliminary experiments were carried out in order to choose a proper eluent for the retained $\mathrm{Cu}^{2+}$ ions after extraction of $2 \mu \mathrm{g}$ copper in $100 \mathrm{~mL}$ solution by the modified disks. The copper was stripped with varying volumes $(5-20 \mathrm{~mL})$ of different acids $\left(\mathrm{HNO}_{3}\right.$, $\mathrm{CH}_{3} \mathrm{COOH}, \mathrm{HCl}$ and $\mathrm{HBr}$ ). Results showed that among four different acid solutions used, $5 \mathrm{~mL}$ of $3.0 \mathrm{~mol} \mathrm{~L}^{-1}$ nitric acid can accomplish the quantitative elution of copper from the membrane disk, while other acids $(5 \mathrm{~mL})$ used are ineffective for the complete elution of these ions. Nitric acid can penetrate into the modified disk and react 
with the SBTD (by protonation of nitrogen atoms and reducing its complex stability) and formation of free copper ion that can easily pass through the membrane.

\section{Influence of flow rate on the separation of copper}

The influence of flow rates of the sample $(2 \mu \mathrm{g}$ of copper in $100 \mathrm{~mL}$ water) and stripping solution from the modified membrane disk on the retention and recovery of $\mathrm{Cu}^{2+}$ ions was investigated. The results showed that in the range of $1-15 \mathrm{~mL} \mathrm{~min}^{-1}$, the retention of copper by the membrane disk is not affected by the sample solution flow rate. At higher flow rate than $15 \mathrm{~mL} \mathrm{~min}{ }^{-1}$, the retention and recovery of the copper reduced considerably.

\section{Optimization of amount of BSTD for modification of disk}

In order to investigate the optimum amount of SBTD on the quantitative extraction by membrane disk, copper ion extraction was conducted by varying the amount of ligand from 0 to $10 \mathrm{mg}$ (Table 2 ). As seen, the extraction of the copper ions is quantitative using above $5 \mathrm{mg}$ of SBTD. Hence, subsequent extraction experiments were carried out with $5 \mathrm{mg}$ of SBTD.

Table 2. Effect of amount of SBTD on $\mathrm{Cu}^{2+}$ extraction

\begin{tabular}{cc}
\hline Amount of SBTD $(\mathrm{mg})$ & \%Recovery ${ }^{\mathrm{a}}\left(\mathrm{Cu}^{2+}\right.$ ions $)$ \\
\hline 0 & $0.8(1.1)^{\mathrm{b}}$ \\
2 & $55.3(1.4)$ \\
4 & $91.2(1.0)$ \\
5 & $100.1(1.0)$ \\
7 & $100.2(1.1)$ \\
10 & $99.8(1.2)$ \\
\hline
\end{tabular}

anitial samples contained $1 \mu \mathrm{g}$ of $\mathrm{Cu}^{2+}$ ions in $100 \mathrm{~mL}$ water; ${ }^{\mathrm{b}}$ values in parentheses are RSDs based on three replicate analysis

\section{Effect of $\mathrm{pH}$ of sample solution on the extraction of copper}

The $\mathrm{pH}$ influence on the recovery of $2 \mu \mathrm{g} \mathrm{Cu}^{2+}$ from $100 \mathrm{~mL}$ solutions was studied in range 2.0 to 8.0 . The $\mathrm{pH}$ was adjusted by using $0.1 \mathrm{~mol} \mathrm{~L}^{-1}$ of either nitric acid or sodium hydroxide solutions and the results are shown in Figure 2. The results obtained indicated that the modified membrane disk through the $\mathrm{pH}$ range of 4.0-8.0 could retain the $\mathrm{Cu}^{2+}$ ions quantitatively. Higher $\mathrm{pH}$ values $(>8.0)$ were not tested because due to the possibility of octadecyl silica hydrolysis of on the disk. At lower $\mathrm{pH}$ than 4.0, the extraction efficiency was reduced. This is most probably due to the protonation of nitrogen donor atoms of SBTD and reduction of its complex formation ability.

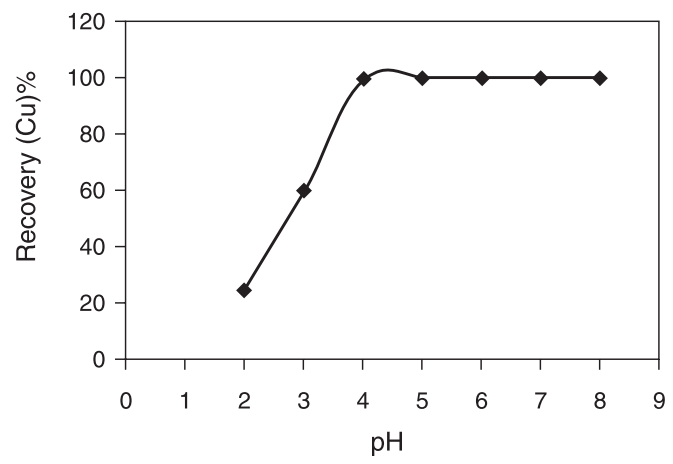

Figure 2. Effect of $\mathrm{pH}$ on the extraction of $\mathrm{Cu}^{2+}$

\section{Determination of break-through volume}

The break-through volume of sample solution by dissolving $2 \mu \mathrm{g}$ of copper in 25,50,100, 250, 500, 750, 1000, 1250, 1500, 1750, 2000, 2250, 2500, 3000 and $3500 \mathrm{~mL}$ of water, was tested and the recommended procedure was followed and the results showed that the extraction by modified membrane disk was found to be quantitative, up to $2500 \mathrm{~mL}$. Thus, the break-through volume for the method is more than $2500 \mathrm{~mL}$.

\section{Detection limit of the proposed method}

The limit of detection (LOD) of the proposed method for the determination of copper was studied under the optimal experimental conditions. The LOD obtained from $C_{L O D}=K_{b} S_{b} m^{-126,27}$ for a numerical factor $\mathrm{K}_{\mathrm{b}}=3$ and concentration factor 500 , is $12.5 \mathrm{pg} \mathrm{mL}^{-1}$.

\section{Retention capacity of the modified disk}

The maximum capacity of the membrane disk modified by $5 \mathrm{mg}$ of SBTD was determined by passing $100 \mathrm{~mL}$ portions of an aqueous solution containing $2000 \mu \mathrm{g}$ copper through the disk, followed by determination of the retained metal ions using ICP-AES. The maximum capacity was found $202 \pm 2 \mu \mathrm{g}$ of copper.

\section{Separation of $\mathrm{Cu}^{2+}$ ions from synthetic samples}

In order to investigate the selective separation and determination of $\mathrm{Cu}^{2+}$ ion from their binary mixtures with diverse metal ions, an aliquot of aqueous solution $(100 \mathrm{~mL})$ containing $2 \mu \mathrm{g} \mathrm{Cu}{ }^{2+}$ ions and various amounts of $\mathrm{Na}^{+}, \mathrm{K}^{+}, \mathrm{Cr}^{3+}(100 \mathrm{mg}), \mathrm{Mg}^{2+}, \mathrm{Ca}^{2+}, \mathrm{Sr}^{2+}$ and $\mathrm{Zn}^{2+}$ $(50 \mathrm{mg})$ and $\mathrm{Co}^{2+}, \mathrm{Ni}^{2+}$ and $\mathrm{Ag}^{+}(30 \mathrm{mg})$ was taken and the recommended procedure was followed and the results show that the copper ions in the binary mixtures are retained almost completely by the modified membrane disk. Meanwhile, retention of other cations by the disk is relatively low.

In order to assess the applicability of the method to real samples, with different matrices containing varying amounts of a variety of ions, it was applied to the determination of copper in spring water and waste water samples, and the results are summarized in Table 3, respectively. As seen, the results of three analyses of each sample show that, in all cases, the recovery of the copper ions is almost quantitative.

Table 3. Determination of copper in spring water and wastewater samples

\begin{tabular}{lcc}
\hline Sample & $\begin{array}{c}\mathrm{Cu} \mu \mathrm{g} \mathrm{mL} \mathrm{m}^{-1} \\
(\text { SPE-ICP-AES) }\end{array}$ & $\begin{array}{c}\mathrm{Cu} \mu \mathrm{g} \mathrm{mL} \mathrm{m}^{-1} \\
(\mathrm{ICP}-A E S)\end{array}$ \\
\hline Spring water 1 & $1.5(0.3)^{\mathrm{b}}$ & $1.4(1.5)^{\mathrm{a}}$ \\
Spring water 2 & $1.2(1.1)$ & $1.3(1.0)^{\mathrm{a}}$ \\
Spring water 3 & $1.4(1.3)$ & $1.4(1.0)^{\mathrm{a}}$ \\
Wastewater 1 & $10.1(0.7)$ & $10.2(0.2)$ \\
Wastewater 2 & $10.5(0.5)$ & $10.7(0.2)$ \\
\hline
\end{tabular}

${ }^{\mathrm{a}}$ Measurements were done after ten-fold concentration by evaporation; ${ }^{b}$ values in parentheses are RSDs based on three replicate analysis

\section{Determination of copper ions in black tea, hot and black pepper samples}

The proposed method was also applied to determination of copper ions in two black tea, hot pepper and black pepper samples and the 
results are given in Table 4. As can be seen, the amount of copper in black tea, hot and black pepper samples can be accurately determined with the proposed method.

Table 4. Determination of copper in black tea samples

\begin{tabular}{lcc}
\hline Sample & $($ SPE with ICP-AES) & $(\text { ICP-AES })^{\mathrm{a}}$ \\
\hline Iranian black tea (Lahijan) & $45.50(1.3)^{\mathrm{b}}$ & $46.30(1.2)$ \\
Indian black tea (Seylon) & $37.92(1.3)$ & $38.82(1.2)$ \\
Hot pepper & $30.4(1.3)$ & $30.2(1.6)$ \\
Black pepper & $29.6(1.6)$ & $29.7(1.4)$ \\
\hline
\end{tabular}

${ }^{\mathrm{a}}$ Measurements were done after four times concentration by evaporation; ${ }^{\mathrm{b}}$ values in parentheses are RSDs based on three replicate analysis

\section{Analysis of copper ions in standard biological samples}

The accuracy and applicability of the proposed method has been applied to the determination of copper in National Institute for Environmental Studies ( NIES) No. 1 Peppcrbush; No. 3 Chlorella; No. 5 Human Hair and No. 7 Tea Leaves and the results are given in Table 5, which are in good agreement with the certified values.

Table 5. Analysis of copper in biological samples

\begin{tabular}{lll}
\hline Sample & Composition $\left(\mu \mathrm{g} \mathrm{g}^{-1}\right)$ & Found $\left(\mu \mathrm{g} \mathrm{g}^{-1}\right)$ \\
\hline NIES , No. 1 & $\mathrm{K}, 1.51 \pm 0.06 ; \mathrm{Mn}, 0.203 \pm 0.107 ;$ & $\mathrm{Cu}, 11.8 \pm 1.1^{\mathrm{b}}$ \\
Pepperbush & $\mathrm{Mg}, 0.408 \pm 0.020 ; \mathrm{Ca}, 1.38 \pm 0.07 \%$ & \\
& $\mathrm{Cd}, 6.7 \pm 0.5 ; \mathrm{Ni}, 8.7 \pm 0.6 ;$ & \\
& $\mathrm{Fe}, 205 \pm 17 ; \mathrm{Co}, 23 \pm 3 ; \mathrm{Pb}, 5.5 \pm 0.8 ;$ \\
& $\mathrm{Cu}, 12 \pm 1 ; \mathrm{Zn}, 340 \pm 20 ; \mathrm{Ba}, 165 \pm 10 ;$ \\
& $\mathrm{Na}, 106 \pm 13 ; \mathrm{Rb}, 75 \pm 4 ; \mathrm{Sr}, 36 \pm 4 ;$ \\
& As, 2.3 $\pm 0.3 ; \mathrm{P},(1100) ; \mathrm{Cr}(1.3) ;$ & \\
& $\mathrm{Cs},(1.2) ; \mathrm{Tl},(0.13) ; \mathrm{Hg},(0.056)$
\end{tabular}

NIES, No. $3^{c} \quad \mathrm{~K}, 1.24 \pm 0.02 ; \mathrm{Mg}, 0.33 \pm 0.02$;

Chlorella $\quad \mathrm{Ca}, 0.46 \pm 0.03 ; \mathrm{Fe}, 0.185 \pm 0.010$

$\mathrm{Cu}, 34.5 \pm 0.5$

$\mathrm{P}(1.7) \% ; \mathrm{Zn}, 205 \pm 10 ; \mathrm{Sr}, 40 \pm 3$;

Co, $0.87 \pm 0.05$; Cd, (0.026);

$\mathrm{Mn}, 69 \pm 5 ; \mathrm{Cu}, 34.5 \pm 0.3$

Sc, (0.013)

NIES, No. $5 \quad \mathrm{~Pb}, 6.0$; Cd, 0.20; K, 34;

Human Hair Rb. 0.19; Sb, 0.07; Zn, 169;

$\mathrm{Al}, 240 ; \mathrm{Fe}, 225 ; \mathrm{Mg}, 208$;

$\mathrm{Hg}, 4.4 ; \mathrm{Sc}, 0.05$; Se, 1.4;

$\mathrm{Na}, 26$; $\mathrm{Sr}, 2.3 ; \mathrm{Ti}, 3.2$;

Ca, 728; Cr, 1.4; Ba, 2.2;

$\mathrm{Co}, 0.10 ; \mathrm{Mn}, 5.2 ; \mathrm{Cu}, 16.3$;

$\mathrm{Ni}, 1.8$

N1ES, No.7 Pb, 0.80; Cd, 0.030; Sb, 0.014;

Tea Leaves $\mathrm{Zn}, 33$; $\mathrm{Cr}, 0.15$; Al, 775;

$\mathrm{Mg}, 1530 ; \mathrm{Ba}, 5.7 ; \mathrm{K}, 18600$;

Sc, 0.011; Na, 15.5; Sr, 3.7;

Ca, 3200; Cs, 0.22; Co, 0.12;

$\mathrm{Mn}, 7.00 ; \mathrm{Ni}, 6.5 ; \mathrm{Cu}, 7.0$

a NIES: National Institute of Environmental Studies reference materials; baverage of five determinations \pm standard deviation and ${ }^{\mathrm{c}} 3$ (Values in parentheses were approximate and not certified).

\section{Comparison of concentration factor of this work and other reports}

The concentration factor of the proposed method and previously reported are compared in Table 6 . As it is obvious, the concentration factor of the method by using BSTD is superior to those previously reported $^{17,21,22,29-33}$.

Table 6. Comparison of concentration factor of this work and other reports

\begin{tabular}{ccc}
\hline Metal ions & Concentration factor & Ref. \\
\hline $\mathrm{Cu}^{2+}$ & 400 & 29 \\
$\mathrm{Ag}^{+}$ & 400 & 21 \\
$\mathrm{Ce}^{3+}$ & 200 & 22 \\
$\mathrm{Cu}^{2+}, \mathrm{Zn}^{2+}, \mathrm{Mn}^{2+}$ & 25 & 30 \\
$\mathrm{Co}^{2+}, \mathrm{Cu}^{2+}$ & 100 & 31 \\
$\mathrm{UO}_{2}^{2+}$ & 100 & 32 \\
$\mathrm{~Pb}^{2+}$ & 100 & 33 \\
$\mathrm{~Pb}^{2+}$ & 100 & 17 \\
$\mathrm{Cu}^{2+}$ & 500 & This work \\
\hline
\end{tabular}

\section{CONCLUSIONS}

The proposed method has the following advantageous: The method is relatively rapid, the time taken for the separation, and analysis of copper in a $500 \mathrm{~mL}$-water sample is at the most $35 \mathrm{~min}$ per sample. It can selectively separate $\mathrm{Cu}^{2+}$ ions from other metal ions associated, even much higher concentrations. The method can be successfully applied to separation and determination of ultra trace $\left(12.5 \mathrm{ng} \mathrm{L}^{-1}\right)$ amounts of copper in environmental and biological samples.

\section{ACKNOWLEDGMENT}

The author thanks the Tehran University Research Council for support of this work.

\section{REFERENCES}

1. Agency for Toxic Substances and Disease Registry; Toxicological Profile for Copper (Draft for public Comment), Aylanta, GA: U.S. Department of Health and Human Services, Public Health Service, 2002.

2. Marczenko, Z.; Separation and Spectrophotometric Determination of Elements, $1^{\text {st }}$ ed., Ellis Harwood: London, 1986.

3. Tian, Y. H.; Pipalnik, R.; Fanger, H. V.; J. Radioanal. Nucl. Chem. 1990, $139,43$.

4. Jackson, K. W.; Mahmood, T. M.; Anal. Chem. 1994, 66, 252R.

5. Pournaghi-Azar, M. H.; Dastangoo, H.; Anal. Chim. Acta 2000, 405, 135.

6. Poursaberi, T.; Haji-agha Babaei, L.; Yousefi, M.; Rouhani, S.; Shamsipur, M.; Kargar-Razi, M.; Moghimi, A.; Aghabozorg, H.; Ganjali, M. R.; Electroanalysis 2001, 13, 1513.

7. Montaser, A.; Golightly, D.W.; Inductively Coupled Plasma in Analytical Atomic Spectrometry, 1987.

8. Rossi, A. V.; Magalhães, M. E. A.; Tubino, M.; Analusis 1994, 22, 465.

9. Juang, R. S.; Huang, I. P.; Sep. Sci.Technol. 2000, 35, 869.

10. Walton, H. F.; Rocklin, R. D.; CRC press, Boca Raton, FL, 1990, chap. 11.

11. Burn, D. T.; Tongkananurk, N.; Anal. Chim. Acta 1989, 219, 323.

12. Yamini, Y.; Tamaddon, A.; Talanta 1999, 49, 119.

13. Izatt, R. M.; Bradshaw, J. S.; Bruening, R. L.; Pure Appl. Chem. 1996, 68, 1237.

14. Cai, Y.; Baynon, J. M.; J. Chromatogr. Sci. 1995, 33, 89.

15. Yamini, Y.; Alizadeh, N.; Shamsipur, M.; Anal. Chim. Acta 1997, 335, 69.

16. Poole, C. F.; Poole, S. K.; Seibert, D. S.; Chapman, C. M.; J. Chromatogr., B: Biomed. Sci. Appl. 1997, 689, 245.

17. Hashemi, O. R.; Raoufi, F.; Ganjali, M. R.; Moghimi, A.; Kargar-Razi, M.; Aghabozorg, H.; Shamsipur, M.; Anal. Sci. 2000, 16, 1221.

18. Hashemi, O. R.; Kargar-Razi, M.; Raoufi, F.; Moghimi, A.; Aghabozorg, H.; Ganjali, M. R.; Microchem. J. 2001, 69, 1.

19. Ghasemi, Z.; Basiripour, F.; Poursaberi, T.; Salavati-Niasari, M.; Shamsipur, M.; Hashemi, O. R.; Raoufi, F.; Ganjali, M. R.; Int. J. Environ. Anal. Chem. 2001, 81, 233.

20. Haji-agha Babaei, L.; Ghasemi, Z.; Darviche, F.; Shamsipur, M.; Raoufi, F.; Ganjali, M. R.; Anal. Sci. 2001, 17,1305. 
21. Shamsipur, M.; Javanbakht, M.; Ghasemi, Z.; Ganjali, M. R.; Lippolis, V.; Garau, A.; Sep. Purif. Technol. 2002, 28, 141.

22. Shamsipur, M.; Yousefi, M.; Ghasemi, Z.; Haji-agha Babaei, L.; Ganjali, M. R.; Sep. Sci. Technol. 2002, 37, 3525.

23. Ganjali, M. R.; Poursaberi, T.; Haji-agha Babaei, L.; Rouhani, S.; Yousefi, M.; Kargar-Razi, M.; Moghimi, A.; Aghabozorg, H.; Shamsipur, M.; Anal. Chim. Acta 2001, 440, 81.

24. Ganjali, M. R.; Zargazi, M. H.; Mohajeri, A.; Pol. J. Chem. 2001, 75, 743.

25. Ganjali, M. R.; Rouhollahi, A.; Mardan, A. R.; Shamsipur, M.; J. Chem. Soc., Faraday Trans. 1998, 94, 1959.

26. ACS Committee on Enviromental Improvement; Anal. Chem. 1980, 52, 2242.
27. Ingel, J. D.; Crouch, S. R.; Spectrochemical Analysis, Prentice Hall; Englewood Cliffs: New Jersey, 1988.

28. Ichinoki, S.; Yamazaki, M.; Anal. Chem. 1985, 57, 2219.

29. Ganjali, M. R.; Ghasemi, Z.; Salavati-niasari, M.; Haji-agha Babaei, L.; Chem. Anal. (Warsaw, Pol.) 2002, 47, 619.

30. Hutchinson, S.; Kearney, G. A.; Horne, E.; Lynch, B.; Glennon, J. D.; Kervey, M. A. M.; Harris, S.; Anal. Chim. Acta 1994, 291, 269.

31. Čundeva, K.; Stafilov, T.; Pavlovska, G.; Microchem. J. 2000, 65, 165.

32. Shamsipur, M.; Ghiasvand, A. R.; Yamini, Y.; Anal. Chem. 1999, 71, 4892.

33. Horwitz, E. P.; Dirtz, M. L.; Rhoads, S.; Felinto, C.; Gale, N. H.; Houghton, J.; Anal. Chim. Acta 1994, 292, 263. 